\title{
Parametric Description of the Stationary Helical Vortex in a Hydrodynamic Vortex Chamber
}

Shtork, S. I.; Gesheva, E. S.; Kuibin, P. A.; Okulov, V. L.; Alekseenko, S. V.

Published in:

Journal of Applied Mechanics and Technical Physics

Link to article, DOI:

$10.1134 /$ S0021894420030062

Publication date:

2020

Document Version

Peer reviewed version

Link back to DTU Orbit

Citation (APA):

Shtork, S. I., Gesheva, E. S., Kuibin, P. A., Okulov, V. L., \& Alekseenko, S. V. (2020). Parametric Description of the Stationary Helical Vortex in a Hydrodynamic Vortex Chamber. Journal of Applied Mechanics and Technical Physics, 61(3), 359-367. https://doi.org/10.1134/S0021894420030062

\section{General rights}

Copyright and moral rights for the publications made accessible in the public portal are retained by the authors and/or other copyright owners and it is a condition of accessing publications that users recognise and abide by the legal requirements associated with these rights.

- Users may download and print one copy of any publication from the public portal for the purpose of private study or research.

- You may not further distribute the material or use it for any profit-making activity or commercial gain

- You may freely distribute the URL identifying the publication in the public portal 


\title{
PARAMETRIC DESCRIPTION OF THE STATIONARY HELICAL VORTEX IN A HYDRODYNAMIC VORTEX CHAMBER
}

\author{
S. I. Shtork ${ }^{a, b}$, E. S. Gesheva ${ }^{a,{ }^{*}}$, P. A. Kuibin ${ }^{a, b,{ }^{*}}$, \\ V. L. Okulov ${ }^{b, c}$, and S. V. Alekseenko ${ }^{a}$
}

UDC 532.5.01

\begin{abstract}
A swirling flow in a tangential-type hydrodynamic chamber with stationary vortex structures is experimentally investigated. The main attention is paid to determining the geometric and kinematic parameters necessary for a correct description of helical vortices and their spatial structure, in particular, to testing the possibility of a theoretical description of the limiting case where the vortex becomes stationary, i.e., its rotation frequency (or precession frequency) becomes zero. It is shown that the theory of helical vortices ensures a sufficiently accurate prediction of conditions for the appearance of their stationary (motionless) states.
\end{abstract}

Keywords: vortex dynamics, helical vortex, vortex chamber, parametric description.

\section{DOI:}

\section{INTRODUCTION}

Swirling motion of the medium is the basis of operation of many power engineering facilities, including combustion chambers of coal dust boilers [1-3], gas-turbine combustors [4, 5], wind turbines [6], water turbines [7-9], vortex reactors with a centrifugal fluidized bed [10], vortex heat exchangers [11], etc. Vortex flows are frequently encountered in nature, e.g., in the form of intense atmospheric vortices [12, 13], which rather hazardous for people. The interest to studying vortex flows is inspired not only by various applications, but also by complex physical phenomena arising in these flows: laminar-turbulent transition [14], instability and waves [15, 16], vortex breakdown and vortex core precession $[17,18]$.

A typical feature of the vortex filament is the helical shape of its rotation axis [15, 19]. Self-induced shifting of the rotation axis, which occurs due to filament curvature, has to be taken into account in the description of motion of helical vortices [20,21]. A commonly accepted approach formulated at the beginning of the 20th century by Joukowsky [22] is the allowance for only the binormal component of velocity in the analysis of self-induced motion of the helical filament. However, erroneous ideas disproving the classical concept still appear (see the discussion on this issue in [23]). A physical experiment [23] was perform to test these hypotheses. In this experiment, a stationary (motionless) helical vortex generated in a hydrodynamic vortex chamber with tangential swirling of the flow was studied in order to provide experimental justification for the difference between the binormal motion of the helical vortex and the motion of particles along the axis of this vortex $[1,2]$. The choice of a stationary vortex as an object of the study offers some advantages for experimental investigations. In particular, visualization can

${ }^{a}$ Kutateladze Institute of Thermophysics, Siberian Branch, Russian Academy of Sciences, Novosibirsk, 630090

Russia. ${ }^{b}$ Novosibirsk State University, Novosibirsk, 630090 Russia. ${ }^{c}$ Wind Energy Department, Technical University of Denmark, DK-2800 Lyngby, Denmark; shtork@itp.nsc.ru, *gesheva_es@itp.nsc.ru, *kuibin@itp.nsc.ru, vokulov@mail.ru, aleks@itp.nsc.ru. Translated from Prikladnaya Mekhanika i Tekhnicheskaya Fizika, Vol. 61, No. 3, pp. 52-62, May-June, 2020. Original article submitted April 20, 2020; revision submitted April 20, 2020; accepted for publication April 27, 2020.

${ }^{*}$ Corresponding author. 

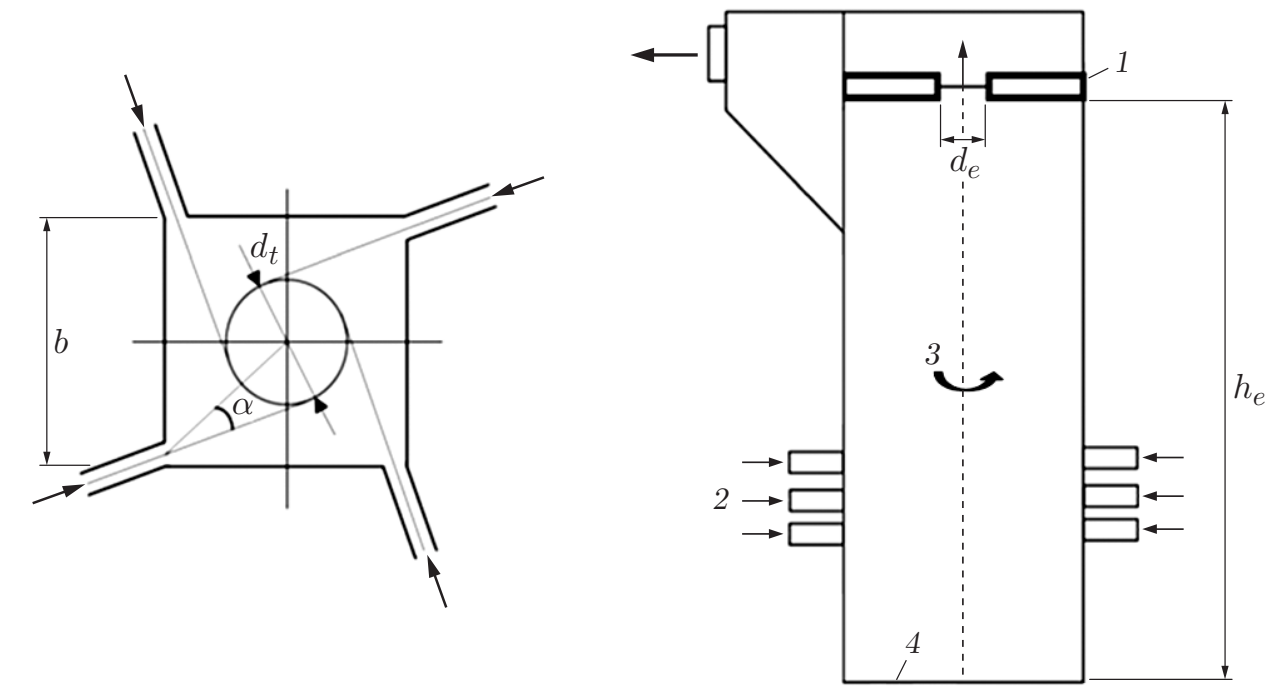

Fig. 1. Schematic of flow swirling and basic parameters of the chamber: (1) diaphragm with the central orifice; (2) nozzles; (3) fluid rotation direction; (4) chamber bottom; the arrows show the inflow and outflow directions.

reveal the basic specific features of the flow and simplify flow quantification owing to application of contactless optical systems [24]. Comparisons of results of visual observations and measurements made it possible to prove the existence of differences between the helical vortex motion (more exactly, the absence of its motion) and intense motion of liquid particles along the vortex axis. As explained in [23], this difference in the motions confirms the validity of the classical approach used to describe self-induced motion of the helical vortex [21, 22].

The present study continues the previous investigations of stationary helical vortices for the purpose of determining the complete set of geometric and kinematic parameters of the stationary helical vortex, which can be used, in particular, for calculating the frequency of vortex rotation (precession frequency) on the basis of the classical theory of motion of the helical vortex $[15,19]$. In this case, the results of vortex motion visualization testify that the precession frequency should be equal to zero because the helical filament does not move in space. If the calculated frequency is also close to zero, the proposed theoretical model can be used to describe flows with stationary helical vortices.

It should be noted that confirmation of the existence of an adequate theoretical model of helical vortices is not only interesting from the viewpoint of determining the fundamental laws of the dynamics of three-dimensional concentrated vortex filaments, but is also important for applications. The analytical model of helical vortices [25] can be used for fast calculations of the operating parameters of vortex facilities [26]. Vortex structures generated in such facilities are usually hard to predict because they induce a complex three-dimensional unsteady swirling flow. In this case, the prediction of the existence of stationary regimes by means of traditional variation of input conditions requires significant time and computational resources [27] or expensive measurement equipment [28]. Flow simulations are complicated by several factors, such as the non-isothermal character of the flow [29] and mutiphase phenomena [30]. In this case, it is extremely important to perform extremely prompt calculations with the use of the analytical formulas [25] for the basic flow parameters, e.g., amplitude-frequency characteristics or instantaneous flow field distributions, and to predict the vortex setup behavior on the basis of these calculations.

\section{EXPERIMENTAL SETUP}

The study was performed in an experimental setup, which is a closed hydraulic contour providing the flow rate of the working fluid (distilled water) up to $8 \mathrm{l} / \mathrm{s}$ [2]. The test section shaped as a square channel $188 \times 188 \times 625 \mathrm{~mm}$ (Fig. 1) was earlier used as tangential combustor model [1]. This shape of the channel was chosen because it is easier to fabricate flat rather than cylindrical side walls for large tangential combustors. As was found in investigations 
(a)

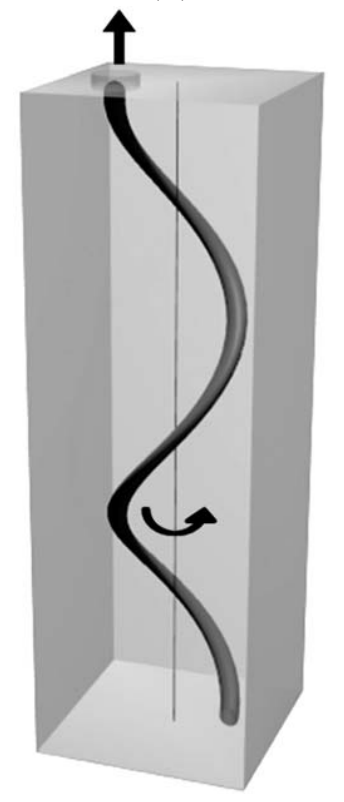

(b)

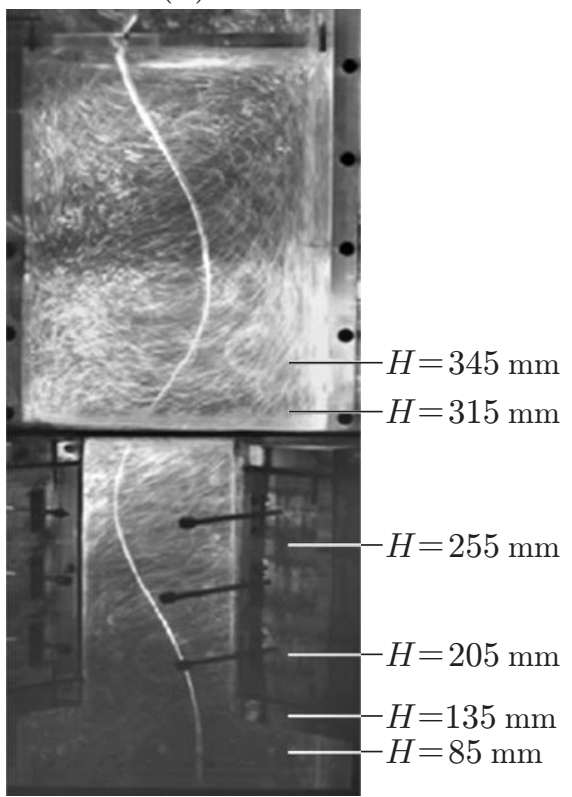

Fig. 2. Stationary helical vortex in the combustor having a diaphragm with a shifted output orifice (the swirl parameter is $S=8.5$, the diaphragm orifice diameter is $d_{e}=60 \mathrm{~mm}$, and the height of diaphragm mounting is $h_{e}=560 \mathrm{~mm}$ ): (a) schematic of the vortex; (b) results of visualization; the arrow shows the direction of flow swirling; $H$ is the height at which PIV measurements of velocity fields were performed.

of the vortex flow in a closed container with polygonal geometry, the cross-sectional shape affects the flow regimes and structure, in particular, at comparatively low Reynolds numbers in the interval Re $=1500-2500$ [31]. It was noted that the flow structure in the axial region remains axisymmetric even if the channel cross section is a square. This conclusion is consistent with the results of experiments performed in the tangential combustor for high turbulence conditions with Reynolds numbers Re $>10000$ [19]. Stabilization of such a flow structure is favored, in particular, by the formation of secondary vortices at the combustor corners, which make the streamlines in the peripheral regions more smooth [31]. In addition, flat side walls of a square eombustor do not generate optical distortions, which allows contactless optical methods to be used for studying the flow.

Tangentially directed rectangular nozzles (a total of 12 nozzles) with the exit size of $14 \times 23 \mathrm{~mm}$ generate a vortex flow with a vertical rotation axis in the test section. The degree of flow swirling is defined by the geometric swirl parameter $S=b d_{t} / A_{t}\left(b=188 \mathrm{~mm}\right.$ is the combustor width, $d_{t}$ is the diameter of the circumference to which the input nozzles are tangentially aligned, and $A_{t}$ is the area of the input nozzles) [19]. The structure of the nozzle blocks allows one to change the nozzle turning angle $\alpha$ determining the diameter $d_{t}$, thus, varying the swirl parameter in a wide range and $S=0-8$.

As was noted above, the flow regime in the combustor is also characterized by the Reynolds number Re, which is determined on the basis of the vortex chamber width $b$ and mean mass flow rate $W: \operatorname{Re}=b W / \nu(\nu$ is the kinematic viscosity). The results reported in the present paper were obtained at high Reynolds numbers $\operatorname{Re}>15000$ corresponding to the self-similar flow regime [2].

The aerodynamic structure of he vortex flow is controlled by replaceable constricting diaphragms with the central (see Fig. 1) or shifted (Fig. 2) orifice. Owing to flow constriction at the exit, a concentrated helical filament is formed; its geometry is determined by the shape of the chamber bottom and diaphragm geometry. For example, a straight-line vortex filament is formed in the case of the central orifice [24], while the filament takes a helical shape in the case of the shifted orifice [19]. Specific features of these structure are their steadiness and stability, which significantly simplifies their investigations. 
The flow was visualized by small air bubbles injected into the channel upstream of the test section. As air bubbles have a clear interface between the phases, they ensure distinct light reflection and leave a clearly visible bright trace. Moreover, air bubbles in swirling flows are separated near the rotation axis and visualize it owing to the formation of an air cavity, which is formed even in an unsteady flow [32, 33]. It should be noted that air bubbles were not added to the flow in experiments with measurements in this study: a two-phase mixture was generated only for flow visualization. As the vortex structures were stationary, expensive high-speed cameras were not needed to visualize the flow pattern. Therefore, the visualization results reported below were obtained by a reflex camera with a resolution of $18 \mathrm{Mpixel}$ and with a function of video recording with a rate up to $60 \mathrm{fps}$. The flow was illuminated by a continuous wave laser with a power of $3 \mathrm{~W}$ whose beam was transformed into a plane by a cylindrical lens.

The velocity fields were measured by the POLIS system of particle image velocimetry (PIV). It should be noted that such measurement systems were successfully used, in particular, in complex vortex flows [28, 29]. The flow was seeded with polyamide particles with the mean diameter of $10-20 \mu \mathrm{m}$ ). Control of the PIV system, data acquisition, data storage, and image processing were performed with the use of the ActualFlow software. The PIV system consisted by a double pulse laser and a camera based on the complementary metal-oxidesemiconductor (CMOS) structure. The system operated in a two-frame mode with the measurement frequency of $270 \mathrm{~Hz}$. The time delay between two flashes for determining displacement of particles in a pair of frames was $100 \mu \mathrm{s}$, and the measurement error was within $4 \%$.

The flow in the present study was stationary; as a result, there was no need to use expensive high-speed tomographic PIV systems [28] or special algorithms for phase averaging of velocity [34, 35], which require a large volume of statistical data.

\section{RESULTS OF THE STUDY}

It was experimentally demonstrated $[1,19]$ that an unsteady flow is formed in the examined combustor if the output is fully open. The peak velocities are reached near the side walls of the combustor and a reverse flow is formed in the axial region; a vaguely expressed helical vortex precessing around the geometric axis of the combustor is formed at the reverse flow boundary. The vortex structure becomes stationary if the boundary conditions are modified, i.e., if a diaphragm is mounted in the exit cross section.

If the diaphragm is mounted at the center of the combustor with a flat bottom, a straight-line vortex filament is formed between the chamber bottom and the output orifice [24]. If the orifice in the diaphragm is diagonally shifted, the vortex becomes curved and takes a helical shape (see Fig. 2).

Figure 3 shows the time-averaged (the averaging was performed over more than 200 frames taken at different time instants) profiles of the projections of velocity near the vortex core onto the horizontal and vertical planes ( $V_{t}$ is the tangential velocity and $V_{a}$ is the axial velocity). It should be noted that this velocity in the case of a stationary structure coincides with the velocity induced by the helical vortex filament, in contrast to the case of the precessing vortex for which the averaging with respect to time yields the velocity distribution "blurred" in the azimuthal direction [26]. In the latter case, special algorithms and additional assumptions on the vortex motion character should be used to retrieve the vortex core parameters.

Let us now study the profiles of the tangential velocity $V_{t}$ in the flow with a helical vortex for a fixed height at which velocity measurements were performed, $H=345 \mathrm{~mm}$, and for different values of the Reynolds number Re (see Fig. 3a) and also for $R e=19200$ and different values of the height above the combustor bottom (see Fig. 3b). The tangential velocity measure in the horizontal cross section along the line passing through the combustor center and vortex center is normalized to the mean mass flow rate $W$; the distances from the combustor center $r$ and from the vortex center $r^{*}\left(r^{*}=0\right.$ corresponds to the vortex center) are normalized to the combustor half-width $R=94 \mathrm{~mm}$. It is seen in Fig. 3a that the velocity profile is shifted from the ordinate axis because of shifting and curving of the vortex axis. Figure $3 \mathrm{~b}$ shows the position $\varepsilon$ of the maximum of the tangential velocity at the height $H=345 \mathrm{~mm}$, which was obtained by means of data extrapolation. The tangential velocity profiles for different heights are shifted along the abscissa axis in such a way that the value $V_{t}=0$ is reached at $r^{*}=0$.

Figure 3 also shows the profiles of the axial velocity $V_{a}$ for the flow with a helical vortex for $H=345 \mathrm{~mm}$ and different values of Re (Fig. 3c) and for Re $=19200$ and different heights from the combustor bottom (Fig. 3d). 

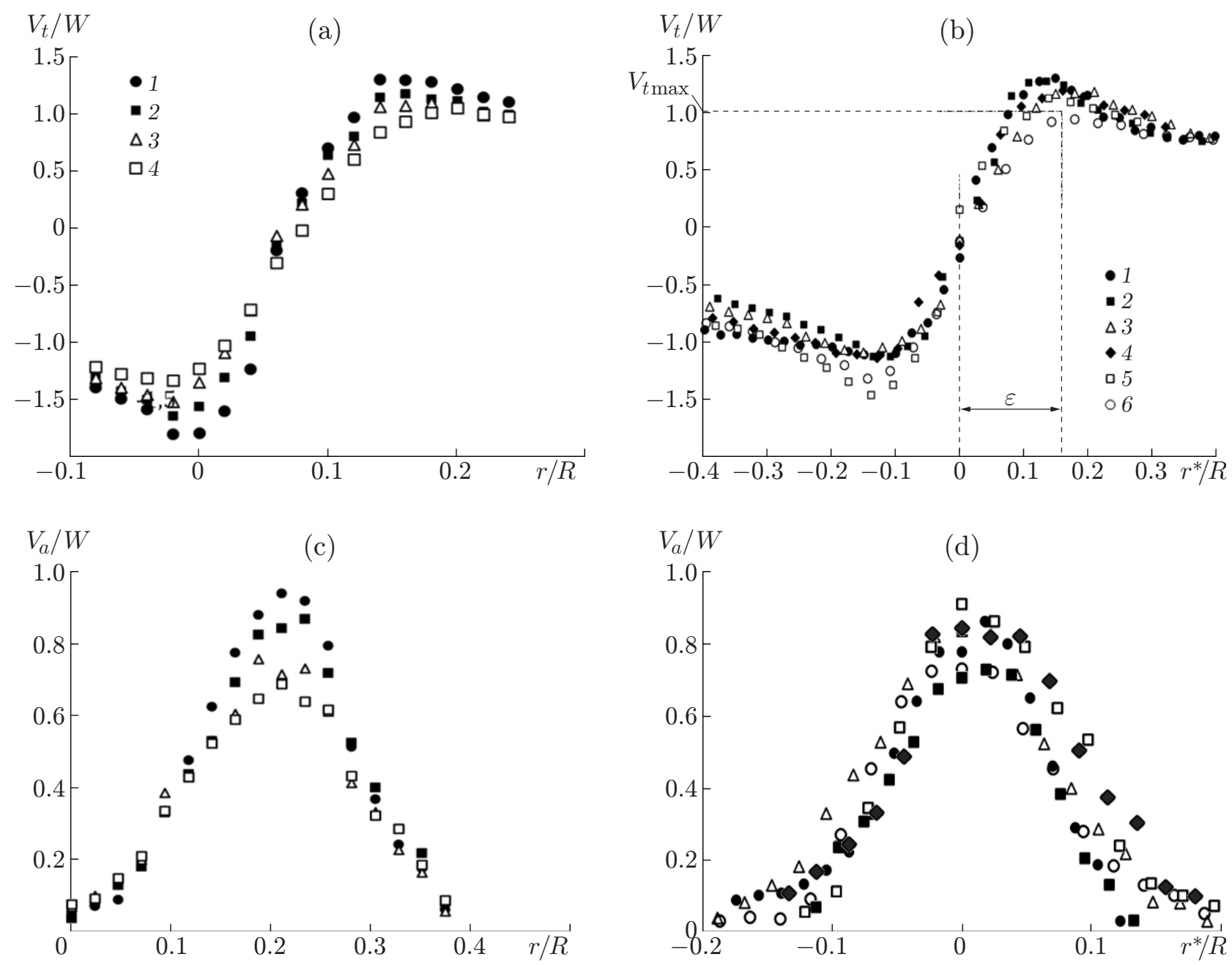

Fig. 3. Profiles of tangential (a and b) and axial (c and d) velocities in the vicinity of the helical vortex for $S=8.5, d_{e}=60 \mathrm{~mm}, h_{e}=560 \mathrm{~mm}$, and different values of Re (a and c) and height above the combustor bottom ( $\mathrm{b}$ and d): ( $\mathrm{a}$ and c) $H=345 \mathrm{~mm}$ and $\mathrm{Re}=14700(1), 19200(2)$, 23600 (3), and 28000 (4); (b and d) $R e=19200$ and $H=85$ (1), 135 (2), 205 (3), 255 (4), 315 (5), and $345 \mathrm{~mm}(6)$.

The profiles were obtained in vertical planes passing through the vertical axis of the combustor and through the vortex center in the horizontal cross section being considered. It is seen in Figs. 3c and 3d that the maximum values of axial velocity are localized near the vortex axis, similar to the case of a straight-line vortex [24], and the axial velocity profiles for different heights (see Fig. 3d) are shifted along the abscissa axis so that the value $V_{a}$ max is reached at $r^{*}=0$.

The data obtained on the velocity field allow direct determination of the vortex structure characteristics: vortex circulation $\Gamma=2 \pi \varepsilon V_{t \max }$, vortex core radius $\varepsilon$, vortex precession radius $a$, pitch of the helical structure $l$, axial velocity $V_{a x}$, and maximum tangential velocity $V_{t}$ max. The axial velocity $V_{a x}$ was determined from the data obtained in the PIV experiment where the velocity field was measured. Based on these data, the vortex core radius $\varepsilon$ was also determined; it was equal to the coordinate at which the maximum tangential velocity $V_{t}$ was reached, also determined from the velocity profiles (see Fig. 3b). The geometric parameters of the helical structure $l$ and $a$ were determined on the basis of the results of vortex structure visualization by means of averaging of the measured variables on 60 frames taken at different times. 


\section{DETERMINATION OF THE STEADINESS CONDITIONS FOR HELICAL VORTICES}

As the vortex is curved, the filament segment under consideration turns out to be located in the velocity field induced by other segments of the filament; therefore, such motion is called the self-induced motion of the vortex filament $[15,22]$. The overall displacement of the vortex structure is also affected by the main flow and by the test section shape (e.g., shape of the side walls). In the present study, all basic components of the resultant rotation are taken into account in considering the vortex precession frequency. The precession frequency is understood as the frequency of passing of the vorticity blob near a fixed point located in the flow or on the wall of the test section, i.e., the frequency $f$ of rotation of the vortex cross section in a fixed plane [15].

Let us determine the precession frequency with allowance for the curvature $\left(\bar{f}_{C}\right)$, swirling $\left(\bar{f}_{\tau}\right)$, presence of the test section walls $\left(\bar{f}_{R}\right)$, and axial velocity $\left(\bar{f}_{\beta}\right)$. A detailed description and derivation of all formulas for calculating the precession frequency of the helical vortex in the combustor based on the analysis of binormal velocity of the segment of the curved vortex filament can be found in $[25,26]$. In the present case, the formula for the precession frequency is written in the dimensionless form $\left(\bar{f}=2 \pi f R^{2} / \Gamma\right)$ as

$$
\bar{f}_{t h}=\bar{f}_{C}+\bar{f}_{\tau}+\bar{f}_{R}+\bar{f}_{\beta},
$$

where

$$
\begin{gathered}
\bar{f}_{C}=-\frac{1}{4 \pi} \frac{R^{2}}{a^{2}} \frac{1}{\tau\left(1+\tau^{2}\right)^{1 / 2}} \ln \left(\frac{a}{\varepsilon}\left(1+\tau^{2}\right)\right), \\
\bar{f}_{\tau}=-\frac{1}{4 \pi} \frac{R^{2}}{a^{2}} \frac{1}{\tau\left(1+\tau^{2}\right)^{1 / 2}}\left[\ln \left(\frac{\tau}{1+\tau^{2}}\right)+\right. \\
\quad+\frac{1+1,455 \tau+1,723 \tau^{2}+0,711 \tau^{3}+0,616 \tau^{4}}{\tau+0,486 \tau^{2}+1,176 \tau^{3}+\tau^{4}}-\frac{1}{4}-2 \frac{\left(1+\tau^{2}\right)^{1 / 2}}{\tau}(2) \\
\bar{f}_{R}=\frac{1}{2 \pi} \frac{R^{2}}{a^{2}} \frac{1+\tau^{2}}{\tau^{2}}\left(\frac{\tilde{a}^{2}}{\tilde{R}^{2}-\tilde{a}^{2}}-k \ln \frac{\tilde{R}^{2}-\tilde{a}^{2}}{\tilde{R}^{2}}\right), \quad \bar{f}_{\beta}=-\frac{1}{2 \pi} \frac{R^{2}}{a^{2}} \frac{\beta}{\tau^{2}} ; \\
k=\frac{1}{12}\left(\frac{9 \eta}{\left(1+\eta^{2}\right)^{1 / 2}}-\frac{7 \eta^{3}}{\left(1+\eta^{2}\right)^{3 / 2}}-\frac{3 \tau}{\left(1+\tau^{2}\right)^{1 / 2}}+\frac{\tau^{3}}{\left(1+\tau^{2}\right)^{3 / 2}}\right), \quad \beta=\frac{2 \pi l}{\Gamma}, \quad \tau=\frac{l}{a}, \quad \eta=\frac{l}{R} .
\end{gathered}
$$

The quantities with the tilde are defined as

$$
\tilde{x}=2 x \frac{\exp \left(\sqrt{1+x^{2} / l^{2}}-1\right)}{\sqrt{1+x^{2} / l^{2}}+1} .
$$

For calculating the vortex core precession frequency by Eq. (1), it is necessary to determined such parameters as the vortex core radius $\varepsilon$, vortex precession radius $a$, pitch of the helical vortex $l$ (Fig. 4), vortex circulation $\Gamma$, and velocity at the vortex chamber axis $V_{a x}$. All parameters obtained by means of visualization of the PIV experiment are summarized in Table 1.

Substituting the values of the vortex parameters into Eqs. (2), we obtain the values of $\bar{f}_{C}, \bar{f}_{\tau}, \bar{f}_{R}$, and $\bar{f}_{\beta}$. In turn, substituting these values into Eq. (1), we find the dimensionless precession frequency $\bar{f}_{\text {th }}$ (Table 2).

The dimensionless frequency of precession of the helical vortex around the chamber axis with allowance for the measurement error $( \pm 0.1)$ is close to zero (for comparison, for $R e=19200$, the dimensionless frequency of rotation of fluid particles around the vortex axis is $\bar{f}_{r o t}=1.06$ ). Thus, according to the analytical formulas, the helical vortex does not rotate around the chamber axis, i.e., it is stationary. This result is confirmed by experimental data: visualization of vortices does not reveal their rotation around the chamber axis. Therefore, the vortex precession frequency calculated by the analytical method agree well with the experimental data, which confirms that the assumptions used in the theory of helical vortices are correct and they can be applied in the limiting case considered here (stationary regime).

The results obtained in the study offer an explanation of the steady character of vortices observed in experiments: it can be attributed to the influence of the terms in the right side of Eq. (1), which have different signs and compensate for each other in certain cases; as a result, the vortex becomes stationary. It should be noted that it is important to take into account all parameters mentioned above, i.e., curvature and swirling of the vortex filament, velocity induced by the chamber wall, and velocity at the chamber axis in determining the vortex precession frequency. 


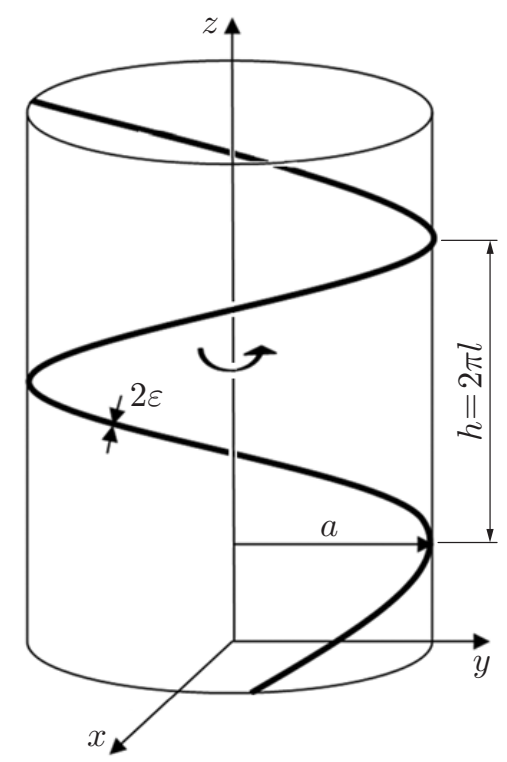

Fig. 4. Parameters of the helical vortex filament.

Table 1. Parameter of the helical vortex

\begin{tabular}{c|c|c|c|c|c|c|c}
\hline$H, \mathrm{~mm}$ & $\varepsilon, \mathrm{m}$ & $\tau$ & $a, \mathrm{~m}$ & $R, \mathrm{~m}$ & $l, \mathrm{~m} / \mathrm{rad}$ & $\Gamma, \mathrm{m}^{2} / \mathrm{s}$ & $V_{a x}, \mathrm{~m} / \mathrm{s}$ \\
\hline 85 & 0.0140 & 1.5598 & 0.0440 & 0.094 & 0.0686 & 0.2375 & 0.080 \\
135 & 0.0143 & 1.4920 & 0.0455 & 0.094 & 0.0686 & 0.2489 & 0.068 \\
205 & 0.0152 & 1.5527 & 0.0442 & 0.094 & 0.0686 & 0.2665 & 0.057 \\
255 & 0.0156 & 1.5961 & 0.0430 & 0.094 & 0.0686 & 0.2843 & 0.048 \\
315 & 0.0160 & 1.5251 & 0.0450 & 0.094 & 0.0686 & 0.2875 & 0.035 \\
345 & 0.0160 & 1.5240 & 0.0450 & 0.094 & 0.0690 & 0.2815 & 0.023
\end{tabular}

Table 2. Results of the analytical calculation of the dimensionless precession frequency

\begin{tabular}{c|c|c|c|c|c}
\hline$H, \mathrm{~mm}$ & $\bar{f}_{C}$ & $\bar{f}_{\tau}$ & $\bar{f}_{\beta}$ & $\bar{f}_{R}$ & $\bar{f}_{t h}$ \\
\hline 85 & -0.2989 & 0.2969 & -0.3415 & 0.3286 & -0.015 \\
135 & -0.2952 & 0.2969 & -0.2908 & 0.2715 & -0.018 \\
205 & -0.2880 & 0.2963 & -0.2754 & 0.2544 & -0.013 \\
255 & -0.2884 & 0.3003 & -0.2718 & 0.2443 & -0.017 \\
315 & -0.2791 & 0.2937 & -0.2821 & 0.2570 & -0.010 \\
345 & -0.2793 & 0.2939 & -0.3661 & 0.3373 & -0.014
\end{tabular}




\section{CONCLUSIONS}

The geometric and kinematic parameters of swirling flows corresponding to regimes with stationary helical vortices were determined in an experimental study. Based on these data for the limiting case of vanishing rotation (motionless vortex), the possibility of describing stationary helical vortices by the known analytical formula for calculating the precession frequency of helical vortices [25] was verified. It was found that this formula is able not only to ensure an accurate prediction of the emergence of the stationary (motionless) state of the helical vortex, but also to determine effect responsible for that. The results obtained in this study are new and can be used to describe and optimize the operation modes of vortex chambers and combustors.

The part of the study including the velocity field measurements and theoretical analysis was performed within the framework of the State Program supporting research performed under the guidance of leading scientists in Russian institutes of higher education (Agreement No. 075-15-2019-1923). Visualization in the experiments was performed within the framework of the State Task of the Kutateladze Institute of Thermophysics of the Siberian Branch of the Russian Academy of Sciences.

\section{REFERENCES}

1. S. V. Alekseenko, S. I. Shtork, "Swirling Flow Large-Scale Structures in a Combustor Model," Russ. J. Engng Thermophys. 2, 231-266 (1992).

2. E. S. Gesheva, I. V. Litvinov, S. I. Shtork, and S. V. Alekseenko, "Analyzing the Aerodynamic Structure of the Swirl Flow in Vortex Burner Models," Teploenergetika, No. 9, 33-41 (2014) [Thermal Engineering 61 (9), 649-657 (2014)].

3. I. S. Anufriev, O. V. Sharypov, A. A. Dekterev, et al., "Study of Flow Structure in a Four-Vortex Furnace Model," Teplofiz. Aeromekh. 24 (6), 873-879 (2017) [Thermophys. Aeromech. 24 (6), 849-955 (2017)].

4. P. M. Anacleto, E. C. Fernandes, M. V. Heitor, S. I. Shtork, "Swirl Flow Structure and Flame Characteristics in a Model Lean Premixed Combustor," Combust. Sci. Technol. 175 (8), 1369-1388 (2003).

5. F. Luckoff, M. Sieber, C. O. Paschereit, K. Oberleithner, "Characterization of Different Actuator Designs for the Control of the Precessing Vortex Core in a Swirl-Stabilized Combustor," Trans. ASME. J. Engng Gas Turbines Power. 140 (4), 041503 (2018).

6. V. L. Okulov, J. N. Sørensen, D. H. Wood, "The Rotor Theories by Professor Joukowsky: Vortex Theories," Progr. Aerospace Sci. 73, 19-46 (2015).

7. I. Litvinov, S. Shtork, E. Gorelikov, et al., "Unsteady Regimes and Pressure Pulsations in Draft Tube of a Model Hydro Turbine in a Range of Off-Design Conditions," Experiment. Thermal Fluid Sci. 91, 410-422 (2018).

8. S. Skripkin, M. Tsoy, P. Kuibin, S. Shtork, "Swirling Flow in a Hydraulic Turbine Discharge Cone at Different Speeds and Discharge Conditions," Experiment. Thermal Fluid Sci. 100, 349-359 (2019).

9. S. Salunkhe, O. El Fajri, S. Bhushan, et al., "Validation of Tidal Stream Turbine Wake Predictions and Analysis of Wake Recovery Mechanism," J. Mar. Sci. Engng. 7, 362-386 (2019).

10. R. Kh. Abdrakhmanov, N. A. Dvornikov, and V. V. Lukasher, "Dynamics of Two-Phase Swirling Flow in a Vortex Chamber with a Lower End Swirler," Teplofiz. Aeromekh. 24 (3), 349-356 (2017) [Thermophys. Aeromech. 24 (3), 339-346 (2017)].

11. A. I. Leont'ev, Yu. A. Kuzma-Kichta, and I. A. Popov, "Heat and Mass Transfer and Hydrodynamics in Swirling Flows (Review)," Teploenergetika, No. 2, 36-54 (2017).

12. A. Yu. Varaksin, M. E. Romash, and V. N. Kopeitsev, Tornado (Fizmatlit, Moscow, 2011) [in Russian].

13. A. Yu. Varaksin and A. A. Mochalov, "Double Helical Spiral as a Possible Mechanism of Generation of Free Nonstationary Air Vortices," Dokl. Akad. Nauk 487 (2), 144-146 (2019).

14. A. V. Boiko, A. V. Dovgal, and V. V. Kozlov, "Instability of Flow Separation at 2D Surface Imperfections in a Low-Speed Air Stream," Teplofiz. Aeromekh. 24 (2), 171-178 (2017) [Thermophys. Aeromech. 24 (2), 167-173 (2017)].

15. S. V. Alekseenke, P. A. Kuybin, and V. L. Okulov, Intraduction into the Theory of Concentrated Vortices (Inst. Thermophys., Siberian Branch, Russian Acad. of Sci., Novosibirsk, 2003) [in Russian].

16. R. I. Mullyadzhanov, R. D. Sandberg, S. S. Abdurakipov, et al., "Propagating Helical Waves as a Building Block of Round Turbulent Jets," Phys. Rev. Fluids 3, 062601(R) (2018). 
17. O. Lucca-Negro, T. O’Doherty, "Vortex Breakdown: A Review," Progr. Energy Combust. Sci. 27, 431-481 (2001).

18. N. Syred, "A Review of Oscillation Mechanisms and the Role of the Precessing Vortex Core (PVC) in Swirl Combustion Systems," Progr. Energy Combust. Sci. 32, 93-161 (2006).

19. S. V. Alekseenko, P. A. Kuibin, V. L. Okulov, S. I. Shtork, "Helical Vortices in Swirl Flow," J. Fluid Mech. 382, 195-243 (1999).

20. J. Boersma, D. H. Wood, "On the Self-Induced Motion of a Helical Vortex," J. Fluid Mech. 384, 263-280 (1999).

21. V. L. Okulov, J. N. Sørensen, "The Self-Induced Motion of a Helical Vortex," J. Fluid Mech. 883, A-5 (2020).

22. N. E. Joukowsky, "Vortex Theory of the Water Propeller," Trudy. Otdel. Fiz. Nauk Obshchestva Lubitelei Estestvoznaniya 16 (14), 1-31 (1912).

23. V. L. Okulov, E. S. Gesheva, P. A. Kuybin, et al., "Difference in the Motion of a Helical Vortex and the Motion of Particles along the Vortex Axis," Teplofiz. Aeromekh. (2020) (in press).

24. E. S. Gesheva, S. I. Shtork, and S. V. Alekseenko, "Investigation of the Characteristics of a Concentrated Vortex in a Tangential Combustor by the PIV Technique and Computer Simulations," Vestn. Novosib. Gos. Univ. Ser. Fizika 9 (3), 39-48 (2014).

25. P. A. Kuibin, V. L. Okulov, "Self-Induced Motion and Asymptotic Expansion of the Velocity Field in the Vicinity of Helical Vortex Filament," Phys. Fluids. 10 (3), 607-614 (1998).

26. I. V. Litvinov, S. I. Shtork, P. A. Kuibin, et al., "Experimental Study and Analytical Reconstruction of Precessing Vortex in a Tangential Swirler," Intern. J. Heat Fluid Flow 42, 251-264 (2013).

27. A. A. Gavrilov, A. V. Sentyabov, A. A. Dekterev, K. Hanjalic, "Vortical Structures and Pressure Pulsations in Draft Tube of a Francis-99 Turbine at Part Load: RANS and Hybrid RANS/LES Analysis," Intern. J. Heat Fluid Flow 63, 158-171 (2017).

28. S. V. Alekseenko, S. S. Abdurakipov, M. Y. Hrebtov, et al., "Coherent Structures in the Near-Field of Swirling Turbulent Jets: A Tomographic PIV Study," Intern. J. Heat Fluid Flow 70, 363-379 (2018).

29. L. M. Chikishev, V. M. Dulin, A. S. Lobasov, and D. M. Markovich, "On the Influence of Large-Scale Vortex Structures on the Flame Shape in a Swirling Jet Flow," Gorenie Vzryv 11 (2), 31-39 (2018).

30. M. A. Pakhomov and V. I. Terekhov, "Effect of Flow Swirling on Heat Transfer in a Gas-Droplet Flow behind Sudden Expansion of the Tube," Teplof. Vys. Temp. 56 (3), 431-438 (2018).

31. I. V. Naumov, S. V. Dvoynishnikov, I. K. Kabardin, M. A. Tsoy, "Vortex Breakdown in Closed Containers with Polygonal Cross Sections," Phys. Fluids 27, 124103 (2015).

32. D. G. Akhmetov and V. V. Nikulin, "Specific Features of Vortex Core Precession in a Cylindrical Chamber," Dokl. Akad. Nauk 431 (6), 755-757 (2010).

33. S. V. Alekseenko, S. I. Shtork, R. R. Yusupov, "Effect of Air Supply into Vortex Flow of Liquid with Various Swirl Parameters," Interfacial Phenomena Heat Transfer. 6, 129-138 (2018). DOI: 10.1615/InterfacPhenomHeatTransfer.2018027133.

34. S. I. Shtork, K. E. Kala, E. C. Fernandes, and M. V. Heitor, "On Formation of Coherent Helical Structures in a Swirling Jet," Pisma v ZhTF 31 (15), 62-68 (2005).

35. I. V. Litvinov, D. K. Sharaborin, S. I. Shtork, "Reconstructing the Structural Parameters of a Precessing Vortex by SPIV and Acoustic Sensors," Experiments Fluids 60, 39 (2019). 